\title{
Solvothermal Syntheses of Two New Thiostannates and an In-situ Energy Dispersive X-ray Scattering Study of their Formation
}

\author{
Nicole Pienack, ${ }^{[\mathrm{a}]}$ Christian Näther, ${ }^{[\mathrm{a}]}$ and Wolfgang Bensch $*[\mathrm{a}]$
}

Keywords: Solvothermal Synthesis / Crystal Structure / In-situ Energy Dispersive X-Ray Diffraction / Thiostannates

\begin{abstract}
Two new thiostannates $(\mathrm{DBNH})_{2} \mathrm{Sn}_{3} \mathrm{~S}_{6}(\mathbf{1})$ and $(\mathrm{DBNH})_{2} \mathrm{Cu}_{6} \mathrm{Sn}_{2} \mathrm{~S}_{8}$ Then reflections of $\mathbf{2}$ start to grow and reflections of 1 occur some (2) were synthesized under solvothermal conditions applying $\mathrm{Cu}$, time later. The appearance of a thiostannate(IV) followed by the Sn, S and DBN (DBN = 1,5-diazabicyclo[4.3.0]non-7-ene). crystallization of a mixed-valent thiostannate(II,IV) suggests Compound 1 is a rare example of a mixed-valent thiostannate. The complex redox reactions occurring under the solvothermal $\mathrm{Sn}$ (II) species appears in the rare trigonal-pyramidal environment conditions. Syntheses without $\mathrm{Cu}$ in the reaction slurry lead to the whereas $\mathrm{Sn}(\mathrm{IV})$ is in a tetrahedral coordination. The chain-anion is formation of $\mathbf{1}$ within a very short time. The results of the in-situ composed of alternating $\mathrm{Sn}_{3} \mathrm{~S}_{4}$ semi-cubes and $\mathrm{Sn}_{2} \mathrm{~S}_{2}$ rings. The studies clearly indicate that the presence of Cu species in solution structure of $\mathbf{2}$ consists of undulated anionic layers and amine retards the nucleation and crystallization of $\mathbf{1}$. The crystalline molecules between the layers. The layers may be viewed as a intermediate was quenched with ex-situ experiments. All syntheses heteroatom $6^{3}$ graphene layer constructed by condensed $\mathrm{CuS}_{3}$ performed with this intermediate do not lead to the crystallization triangles and $\mathrm{SnS}_{4}$ tetrahedra. The two thiostannates coexist which of $\mathbf{1}$ or $\mathbf{2}$, i.e., there is no direct relation between these three was investigated with in-situ energy dispersive X-ray scattering crystalline compounds. The spectroscopic and thermal properties under real solvothermal conditions. Prior to the formation of $\mathbf{1}$ and of $\mathbf{1}$ and $\mathbf{2}$ are also discussed.
\end{abstract}

2 a crystalline intermediate appears which disappears after $60 \mathrm{~min}$.

() WILEY-VCH Verlag GmbH \& Co. KGaA, 69451 Weinheim, Germany, 2007)

[a] University of Kiel, Institute of Inorganic Chemistry,

Max-Eyth-Str. 2, 24118 Kiel, Germany

Fax: +494318801520

E-mail: wbensch@ac.uni-kiel.de

Supporting information for this article is available on the WWW under http://www.eurjic.org/ or from the author.

\section{Introduction}

Applying the solvothermal route several thiostannates have been synthesized using different amines as structure directing agents, e.g in ${ }_{\infty}^{1}\left[\mathrm{SnS}_{2}\right.$. en $]$ (en $=$ ethylenediamine), ${ }^{[1]}\left(\mathrm{C}_{6} \mathrm{H}_{20} \mathrm{~N}_{4}\right)_{2}\left[\mathrm{Sn}_{2} \mathrm{~S}_{6}\right] \cdot 2$ $\mathrm{H}_{2} \mathrm{O},{ }^{[2]} \quad\left(\mathrm{C}_{2} \mathrm{H}_{10} \mathrm{~N}_{2}\right)\left(\mathrm{C}_{2} \mathrm{H}_{9} \mathrm{~N}_{2}\right)_{2}\left[\mathrm{Sn}_{2} \mathrm{~S}_{6}\right],{ }^{[3]} \quad \mathrm{R}_{2} \mathrm{Sn}_{3} \mathrm{~S}_{7} \quad(\mathrm{R}=$ tetramethylammonium TMA,${ }^{[4]} \mathrm{R}=$ diazabicyclooctane DABCO,${ }^{[5]}$ $\mathrm{R}=$ ammonium/tetraethylammonium ATEA, tetraethylammonium TEA $\left.{ }^{[6]}\right), \quad \mathrm{R}_{2}{ }_{2} \mathrm{Sn}_{4} \mathrm{~S}_{9} \quad\left(\mathrm{R}^{\prime}=\right.$ tetrapropylammonium TPA, tetrabutylammonium TBA ${ }^{[6]}$ ) and $(\mathrm{enH})_{4}\left[\mathrm{Sn}_{2} \mathrm{~S}_{6}\right] \cdot{ }^{[7]}$ Beside the interesting structural features, thiostannates are candidates for catalysis applications and chemical sensing. ${ }^{[8-10]}$ In addition, the integration of transition metals (TM) into the network alters the physical and chemical properties. ${ }^{[11]}$ Thiostannates containing transition metals are for example $\left[\mathrm{Ni}(\mathrm{en})_{3}\right]_{2} \mathrm{Sn}_{2} \mathrm{~S}_{6}$, $[\mathrm{Co} \text { (tren) }]_{2} \mathrm{Sn}_{2} \mathrm{~S}_{6}$ (tren $=$ tris(2-aminoethyl)amine), $[\mathrm{Ni}(\text { tren })]_{2} \mathrm{Sn}_{2} \mathrm{~S}_{6},{ }^{[12]}(1,4-$ dabH $\left._{2}\right) \mathrm{Ag}_{2} \mathrm{SnS}_{4} \quad$ (1,4-dab $=$ 1,4-diaminobutane $),{ }^{[13]}$ $(\mathrm{DBUH}) \mathrm{CuSnS}_{3} \quad(\mathrm{DBU}=1,5$-diazabicyclo[4.3.0]non-5-ene $)$, $\left(1,4-\mathrm{dabH}_{2}\right) \mathrm{Cu}_{2} \mathrm{SnS}_{4},{ }^{[14]} \quad\left[\mathrm{Ni}(\mathrm{dien})_{3}\right]_{2} \mathrm{Sn}_{2} \mathrm{~S}_{6} \quad$ (dien =

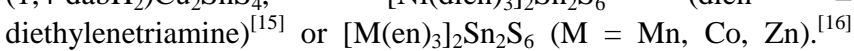
$\mathrm{Sn}(\mathrm{IV})$ is the most common oxidation state in thiostannates and tin sulfides. Until now the number of mixed-valent $\mathrm{Sn}$ sulfides is limited with the most famous example $\mathrm{Sn}_{2} \mathrm{~S}_{3}$ containing $\mathrm{Sn}$ (II) and $\mathrm{Sn}(\mathrm{IV}) .{ }^{[17]}$ However there are some other compounds like $\mathrm{K}_{2} \mathrm{Sn}_{4} \mathrm{Se}_{8}$ [18], $\quad \mathrm{Rb}_{2} \mathrm{Sn}_{4} \mathrm{Se}_{8}, \quad \mathrm{Cs}_{2} \mathrm{Sn}_{4} \mathrm{Se}_{8} \quad$ [19], [ $\left.\mathrm{Sn}_{2} \mathrm{I}_{3}\left(\mathrm{NPPh}_{3}\right)_{3}\right] \quad$ [20], [Sn( $\left.\left.\mu_{3}-\mathrm{NSnMe}_{3}\right)\right]_{4}$ [21], $\mathrm{In}_{2} \mathrm{Sn}_{3} \mathrm{~S}_{7}$ [22], $\mathrm{In}_{6} \mathrm{Sn}_{8} \mathrm{~S}_{19}$ [23], $\mathrm{Sn}_{5} \mathrm{Sb}_{2} \mathrm{~S}_{9}$ [24] and $\mathrm{Cr}_{2} \mathrm{Sn}_{3} \mathrm{Se}_{7}$ [25] featuring the coexistence of $\mathrm{Sn}(\mathrm{II})$ and $\mathrm{Sn}(\mathrm{IV})$.

The well-known problem of the solvothermal method is that in these heterogeneous multi-component processes many parameters like temperature, time, solvent, concentration etc. influence the product formation. Despite several efforts undertaken by different groups we are far from a deeper understanding of the reaction mechanisms occurring under solvothermal conditions [26]. The following example should illustrate the main problems of the solvothermal approach: syntheses performed with $\mathrm{Sb}, \mathrm{S}, \mathrm{Ni}$ and diethylenetriamine as structure director leads to a couple of compounds like [Ni(dien $\left.)_{2}\right]_{2} \mathrm{Sb}_{4} \mathrm{~S}_{8}$ [27], [Ni(dien $\left.)_{2}\right]_{2} \mathrm{Sb}_{4} \mathrm{~S}_{9}$ [28] or $\left[\mathrm{Ni}(\text { dien })_{2}\right]_{3}\left(\mathrm{Sb}_{3} \mathrm{~S}_{6}\right)_{2}[29]$ under almost identical conditions.

In order to shed light on some aspects of the phenomena occurring under solvothermal conditions and to get more information about such 'black-box-reactions', kinetic analyses applying in-situ methods are necessary. During the last few years we successfully investigated several solvothermal reactions applying time resolved in-situ energy dispersive X-ray diffraction (in-situ EDXRD). ${ }^{[30-36]}$ This technique facilitates investigations of the influence of different parameters onto the product formation 
under real reaction conditions. ${ }^{[10,37]}$ The occurrence, growth and decay of crystalline precursors or intermediates can directly be observed which is not possible with ex-situ experiments. In addition, it can be directly monitored whether such transient compounds are related to or necessary for the crystallization of the product. Finally, these studies supply the necessary reaction conditions for quenching such precursors and/or intermediates. In our ongoing work in the field of the solvothermal syntheses of transition metal containing thiostannates we studied solvothermal reactions applying $\mathrm{Cu}, \mathrm{Sn}, \mathrm{S}$ and 1,5-diazabicyclo[4.3.0]non-5-ene (DBN) as solvent and structure directing agent. An interesting observation made during the solvothermal syntheses is the coexistence of two thiostannates of one of which is a $\mathrm{Sn}(\mathrm{II}) / \mathrm{Sn}(\mathrm{IV})$ mixed-valent compound without $\mathrm{Cu}$ and the second contains $\mathrm{Cu}$ and $\mathrm{Sn}(\mathrm{IV})$. This experimental finding requires a systematic study of the solvothermal reaction and therefore is appropriate for investigations using in-situ EDXRD. In the paper we present the solvothermal syntheses of the two new thiostannates $(\mathrm{DBNH})_{2} \mathrm{Sn}_{3} \mathrm{~S}_{6}$ (1) and $(\mathrm{DBNH})_{2} \mathrm{Cu}_{6} \mathrm{Sn}_{2} \mathrm{~S}_{8}$ (2), their crystal structures, the thermal and spectroscopic properties and the results of the in-situ EDXRD studies.

\section{Results and Discussion}

The new thiostannate $(\mathrm{DBNH})_{2} \mathrm{Sn}_{3} \mathrm{~S}_{6}$ (1) crystallizes in the monoclinic space group $P 2_{1} / \mathrm{n}$ with all atoms located on general positions. The three unique Sn atoms are in different environments of $\mathrm{S}$ atoms. $\mathrm{Sn}(1)$ and $\mathrm{Sn}(2)$ are surrounded by $5 \mathrm{~S}$ atoms forming distorted rectangular pyramids (Fig. 1). The Sn-S bonds range from 2.3901(14) to 2.7024(13) $\AA$ for $\operatorname{Sn}(1)$ and from 2.3937(14) to $2.7157(13) \AA ̊$ for $\mathrm{Sn}(2)$, with corresponding S-Sn-S angles varying from $86.64(4)$ to $126.39(6)^{\circ}$ (Table 1).

Table 1. Bond lengths [ $\AA ̊$ ] for $\mathbf{1}$.

\begin{tabular}{ll}
\hline $\mathrm{Sn}(1)-\mathrm{S}(4)$ & $2.3901(14)$ \\
$\mathrm{Sn}(1)-\mathrm{S}(6)$ & $2.3927(14)$ \\
$\mathrm{Sn}(1)-\mathrm{S}(3)$ & $2.4149(12)$ \\
$\mathrm{Sn}(1)-\mathrm{S}(2)$ & $2.5367(14)$ \\
$\mathrm{Sn}(1)-\mathrm{S}(1)$ & $2.7024(13)$ \\
$\mathrm{Sn}(2)-\mathrm{S}(5)$ & $2.3937(14)$ \\
$\mathrm{Sn}(2)-\mathrm{S}(2)^{\mathrm{a}}$ & $2.4020(13)$ \\
$\mathrm{Sn}(2)-\mathrm{S}(3)$ & $2.4201(12)$ \\
$\mathrm{Sn}(2)-\mathrm{S}(4)^{\mathrm{a}}$ & $2.5222(14)$ \\
$\mathrm{Sn}(2)-\mathrm{S}(1)$ & $2.7157(13)$ \\
$\mathrm{Sn}(3)-\mathrm{S}(1)$ & $2.5059(13)$ \\
$\mathrm{Sn}(3)-\mathrm{S}(5)$ & $2.5335(16)$ \\
$\mathrm{Sn}(3)-\mathrm{S}(6)$ & $2.5511(17)$ \\
\hline
\end{tabular}

Symmetry transformations used to generate equivalent atoms: ${ }^{a}:-x+3 / 2, y+1 / 2,-z+1 / 2$

These values are in good agreement with literature data [38, 39]. Interestingly, $\mathrm{Sn}(3)$ is surrounded by only three $\mathrm{S}$ atoms to form a trigonal pyramidal $\mathrm{SnS}_{3}$ unit. This geometry is an indication for $\mathrm{Sn}(\mathrm{II})$ and the bond valence calculations confirm this assignment as well as the mixed-valent character of $(\mathrm{DBNH})_{2} \mathrm{Sn}_{3} \mathrm{~S}_{6}$ (all parameters for the calculations were taken from ref. 40). The Sn-S bond lengths in the $\mathrm{SnS}_{3}$ pyramid are 2.5059(13), 2.5335(16) and 2.5511(17) $\AA$ (average Sn-S: $2.5302 \AA$ ) with the corresponding angles 88.02(4), 88.62(4) and $102.39(6)^{\circ}$. Sn in a trigonal pyramidal environment is quite rare, but some examples are
Ottemannite $\mathrm{Sn}\left(\mathrm{SnS}_{3}\right),{ }^{[41]} \mathrm{C}_{25} \mathrm{H}_{27} \mathrm{NO}_{3} \mathrm{SnS}_{3},{ }^{[42]} \mathrm{C}_{42} \mathrm{H}_{35} \mathrm{AsSnS}_{3},{ }^{[43]}$ and $\mathrm{C}_{42} \mathrm{H}_{35} \mathrm{PSnS}_{3} .{ }^{[44]}$ In these compounds the $\mathrm{Sn}-\mathrm{S}$ bond lengths are in the range of $2.532(10)$ to $2.765(2) \AA$ and the $\mathrm{S}-\mathrm{Sn}-\mathrm{S}$ angles scatter from 83.59(2) to $96.87(3)^{\circ}$. The two $\mathrm{SnS}_{5}$ pyramids and the $\mathrm{SnS}_{3}$ group share common edges to form a so-called $\mathrm{Sn}_{3} \mathrm{~S}_{4}$ semicube (Fig. 1). Neighbored semi-cubes are joined via the terminal $S$ atoms of the $\mathrm{SnS}_{5}$ groups yielding a one-dimensional anionic $\left[\mathrm{Sn}_{3} \mathrm{~S}_{6}\right]^{2-}$ chain running along [010] (Fig. 1). Alternatively, the structure of the chain may be viewed as alternating $\mathrm{Sn}_{3} \mathrm{~S}_{4}$ semicubes and $\mathrm{Sn}_{2} \mathrm{~S}_{2}$ rings.

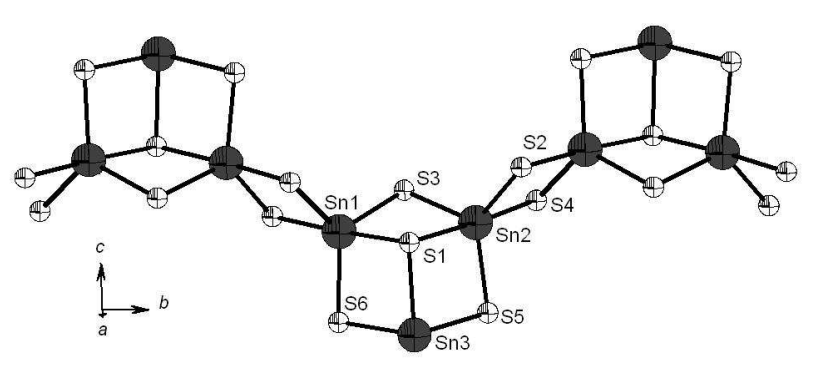

Figure 1: The anionic chain directed along [010] together with atom labelling. The displacement ellipsoids are drawn at the $50 \%$ probability level.

Within the chains the $\mathrm{Sn}_{3} \mathrm{~S}_{4}$ semi-cubes are arranged in a zigzag-like fashion and the amine molecules are located in the cavities of neighbored chains (Fig. 2). In contrast to other compounds with $\mathrm{Sn}_{3} \mathrm{~S}_{4}$ units, the divalent $\mathrm{Sn}$ atom of the $\mathrm{Sn}_{3} \mathrm{~S}_{4}$ semi-cube in $\mathbf{1}$ is trigonally coordinated and has no contact to other sulfur atoms (see Fig. 1). Short S $\cdots \mathrm{H}-\mathrm{N}$ separations $(\mathrm{S}(1)-\mathrm{N}(2)$ : $3.388(17) \AA$ and $\mathrm{S}(2)-\mathrm{N}(4): \quad 3.499(2) \quad \AA$ ) indicate weak hydrogen bonding interactions.

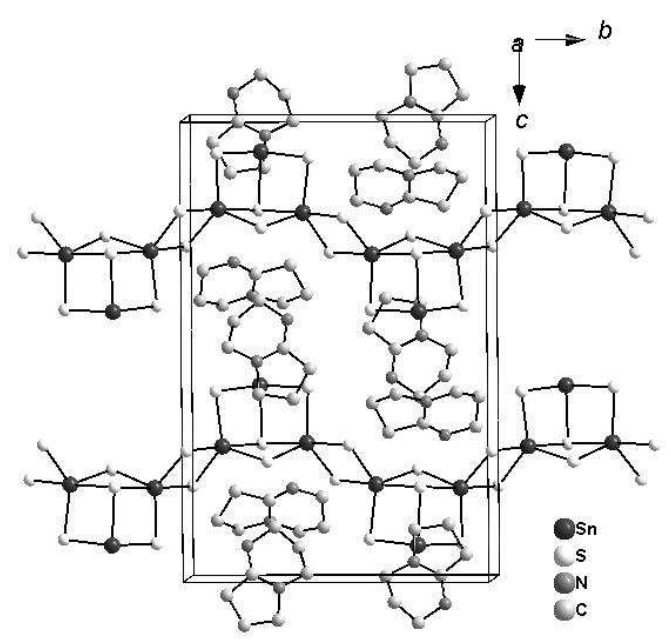

Figure 2: Packing in the $b c$-plane of $(\mathrm{DBNH})_{2} \mathrm{Sn}_{3} \mathrm{~S}_{6}$ with undulated chains along [010]. H atoms are omitted for clarity. 
An interesting observation is that the anionic chain of $(\mathrm{DBNH})_{2} \mathrm{Sn}_{3} \mathrm{~S}_{6}$ shows similar structural motifs like those in the layered thiostannates R-SnS-1 and R-SnS-3 ( $\mathrm{R}=$ organic molecule). ${ }^{[38,39]}$ In these compounds two-dimensional $\left[\mathrm{Sn}_{3} \mathrm{~S}_{7}\right]^{2-}$ and $\left[\mathrm{Sn}_{4} \mathrm{~S}_{9}\right]^{2-}$ anionic layers are observed containing also $\mathrm{Sn}_{3} \mathrm{~S}_{4}$ semicubes which are formed by interconnection of $\mathrm{SnS}_{4}$ tetrahedra. The semi-cubes are joined via two $\mathrm{S}^{2-}$ anions yielding anionic layers with rings consisting of 24 atoms (largest interatomic distances: $10 \AA$ ). The organic molecules act as charge compensating cations and are located above/below the pores and between the layers. ${ }^{[5]}$ In R-SnS-3 the $\mathrm{Sn}_{3} \mathrm{~S}_{4}$ units are joined by $\mathrm{SnS}_{4}$ tetrahedra to form $\left[\mathrm{Sn}_{4} \mathrm{~S}_{9}\right]^{2-}$ layers with elliptical rings measuring about $19.8 \AA \cdot 11.3$ $\AA$ for TBA-SnS-3 (TBA = tetrabutylammonium). ${ }^{[6]}$ Instead of organic structure directors alkali metal ions were used for the synthesis of thiostannates like $\mathrm{Rb}_{2} \mathrm{Sn}_{3} \mathrm{~S}_{7} \cdot 2 \mathrm{H}_{2} \mathrm{O}$ or $\mathrm{Cs}_{4} \mathrm{Sn}_{5} \mathrm{~S}_{12} \cdot 2$ $\mathrm{H}_{2} \mathrm{O}^{[46,47]}$ which also contain $\mathrm{Sn}_{3} \mathrm{~S}_{4}$ groups as well as $\mathrm{Sn}_{2} \mathrm{~S}_{2}$ rings. In $\mathrm{Cs}_{4} \mathrm{Sn}_{5} \mathrm{~S}_{12} \cdot 2 \mathrm{H}_{2} \mathrm{O}$ two $\mathrm{Sn}_{3} \mathrm{~S}_{4}$ semi-cubes are connected via a common corner and with two bridging $\mathrm{S}^{2-}$ anions to form the anionic layers containing elliptical pores with diameter of about 7.3

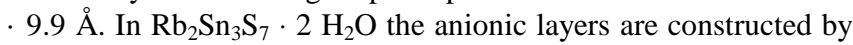
face-sharing semi-cubes and bridging $\mathrm{Sn}_{2} \mathrm{~S}_{2}$ rings.

The second new compound (DBNH) ${ }_{2} \mathrm{Cu}_{6} \mathrm{Sn}_{2} \mathrm{~S}_{8}(2)$ crystallizes in the non-centrosymmetric orthorhombic space group $P c a 2_{1}$ with two unique $\mathrm{Sn}$, six $\mathrm{Cu}$ and eight $\mathrm{S}$ atoms as well as two protonated DBN molecules. All atoms are located on general positions. The structure consists of undulated anionic layers in the (100) plane and protonated amine molecules acting as charge compensating cations between the layers (Fig. 3).

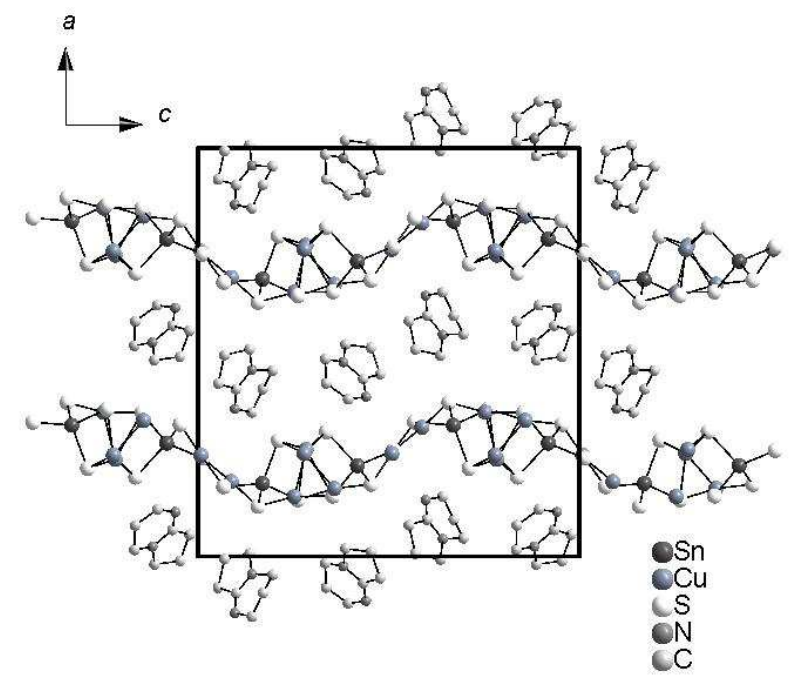

Figure 3: Arrangement of the undulated anionic layers and the cations in compound 2 (view along the $b$-axis). $\mathrm{H}$ atoms are omitted for clarity. Some DBN molecules are disordered and the split positions are not displayed.

Each $\mathrm{Sn}$ atom is in a tetrahedral environment of $\mathrm{S}$ atoms with Sn-S distances from 2.392(2) to 2.414(2) ^ (Table 2) and S-Sn-S angles between $109.98(9)$ and $112.90(8)^{\circ}$, indicating a moderate deviation from ideal tetrahedral geometry. These values match well with data published in literature. ${ }^{[12,48]}$

Table 2. Bond lengths $[\AA]$ for $\mathbf{2}$.

\begin{tabular}{llll}
\hline $\mathrm{Sn}(1)-\mathrm{S}(2)^{\mathrm{a}}$ & $2.392(2)$ & $\mathrm{Cu}(3)-\mathrm{S}(4)$ & $2.238(2)$ \\
$\mathrm{Sn}(1)-\mathrm{S}(3)$ & $2.405(2)$ & $\mathrm{Cu}(3)-\mathrm{S}(8)$ & $2.357(3)$ \\
$\mathrm{Sn}(1)-\mathrm{S}(6)$ & $2.407(2)$ & $\mathrm{Cu}(3)-\mathrm{S}(5)$ & $2.446(3)$ \\
$\mathrm{Sn}(1)-\mathrm{S}(4)$ & $2.414(2)$ & $\mathrm{Cu}(3)-\mathrm{Cu}(4)$ & $2.7755(18)$ \\
$\mathrm{Sn}(1)-\mathrm{Cu}(6)$ & $3.1678(18)$ & $\mathrm{Cu}(3)-\mathrm{Cu}(5)$ & $3.052(2)$ \\
\hline
\end{tabular}

\begin{tabular}{llll}
\hline $\mathrm{Sn}(2)-\mathrm{S}(1)^{\mathrm{b}}$ & $2.385(2)$ & $\mathrm{Cu}(4)-\mathrm{S}(6)^{\mathrm{a}}$ & $2.240(2)$ \\
$\mathrm{Sn}(2)-\mathrm{S}(8)$ & $2.408(2)$ & $\mathrm{Cu}(4)-\mathrm{S}(2)^{\mathrm{a}}$ & $2.246(2)$ \\
$\mathrm{Sn}(2)-\mathrm{S}(5)$ & $2.427(2)$ & $\mathrm{Cu}(4)-\mathrm{S}(5)$ & $2.295(2)$ \\
$\mathrm{Sn}(2)-\mathrm{Cu}(3)$ & $3.0951(13)$ & $\mathrm{Cu}(5)-\mathrm{S}(7)$ & $2.241(2)$ \\
& & $\mathrm{Cu}(5)-\mathrm{S}(5)$ & $2.268(2)$ \\
$\mathrm{Cu}(1)-\mathrm{S}(1)$ & $2.239(2)$ & $\mathrm{Cu}(5)-\mathrm{S}(6)$ & $2.284(2)$ \\
$\mathrm{Cu}(1)-\mathrm{S}(7)^{\mathrm{c}}$ & $2.249(2)$ & $\mathrm{Cu}(5)-\mathrm{Cu}(6)$ & $2.833(2)$ \\
$\mathrm{Cu}(1)-\mathrm{S}(3)$ & $2.282(2)$ & $\mathrm{Cu}(6)-\mathrm{S}(8)^{\mathrm{d}}$ & $2.200(3)$ \\
$\mathrm{Cu}(2)-\mathrm{S}(2)$ & $2.220(3)$ & $\mathrm{Cu}(6)-\mathrm{S}(4)$ & $2.260(3)$ \\
$\mathrm{Cu}(2)-\mathrm{S}(1)^{\mathrm{d}}$ & $2.258(3)$ & $\mathrm{S}(1)-\mathrm{Cu}(2)^{\mathrm{a}}$ & $2.258(2)$ \\
$\mathrm{Cu}(2)-\mathrm{S}(3)$ & $2.277(2)$ & $\mathrm{S}(1)-\mathrm{Sn}(2)$ & $2.385(2)$
\end{tabular}

Symmetry transformations used to generate equivalent atoms: a: $x, y+1, z \quad b^{\prime}:-x+3 / 2, y, z-1 / 2 \quad{ }^{c}:-x+3 / 2, y, z+1 / 2^{d}: x, y-1, z$

All $\mathrm{Cu}$ atoms have bonds to three $\mathrm{S}$ atoms forming distorted $\mathrm{CuS}_{3}$ triangles with the $\mathrm{Cu}$ atoms being located slightly above the planes of the three $\mathrm{S}$ atoms. The $\mathrm{Cu}-\mathrm{S}$ bond lengths scatter between 2.200(3) and 2.446(3) $\AA$ (Table 2) and the corresponding angles are between $97.88(8)$ and $141.84(15)^{\circ}$. All values are in the typical range reported in literature. ${ }^{[14,49,50]} \mathrm{The} \mathrm{Cu}(3)$ to $\mathrm{Cu}(6)$ atoms each have a Cu atom at distances ranging from 2.7755(18) to 3.052(2) $\AA$ (Table 2). Some examples with comparable values for such $\mathrm{Cu}-\mathrm{Cu}$ distances are $\left(\mathrm{enH}_{2}\right)_{0.5} \mathrm{Cu}_{2} \mathrm{SbS}_{3}$ (en = ethylenediamine), (1,3dapH $\left._{2}\right)_{0.5} \mathrm{Cu}_{2} \mathrm{SbS}_{3} \quad$ (1,3-dap $=1,3$-diaminopropane), ${ }^{[51]}$ $\left(\mathrm{C}_{6} \mathrm{~N}_{4} \mathrm{H}_{20}\right)_{0.5} \mathrm{Cu}_{3} \mathrm{Sb}_{2} \mathrm{~S}_{5}{ }^{[52]}$ and $\left(1,4-\mathrm{dabH}_{2}\right) \mathrm{Cu}_{2} \mathrm{SnS}_{4}(1,4-\mathrm{dab}=1,4-$ diaminobutane). ${ }^{[14]}$ In the literature $d^{10}-d^{10}$ interactions are discussed for several sulfides, ${ }^{[53]}$ but in those cases the $\mathrm{Cu}-\mathrm{Cu}$ distances are even shorter than in compound 2.

$\mathrm{CuS}_{3}$ triangles and $\mathrm{SnS}_{4}$ tetrahedra are joined to form six different six-membered $\mathrm{Cu}_{2} \mathrm{SnS}_{3}$ heterorings: $\mathrm{Cu}(4) \mathrm{Cu}(5) \mathrm{Sn}(1) \mathrm{S}_{3}$ (A), $\quad \mathrm{Cu}(1) \mathrm{Cu}(5) \mathrm{Sn}(2) \mathrm{S}_{3} \quad$ (B), $\quad \mathrm{Cu}(1) \mathrm{Cu}(2) \operatorname{Sn}(1) \mathrm{S}_{3} \quad$ (C), $\mathrm{Cu}(2) \mathrm{Cu}(4) \mathrm{Sn}(2) \mathrm{S}_{3} \quad$ (D), $\quad \mathrm{Cu}(4) \mathrm{Cu}(5) \mathrm{Sn}(2) \mathrm{S}_{3} \quad$ (E), and $\mathrm{Cu}(1) \mathrm{Cu}(2) \mathrm{Sn}(2) \mathrm{S}_{3}$ (F) which are condensed in the (100) plane (Fig. 4; left) yielding an undulated layer which may be viewed as a distorted graphene $6^{3}$ layer.

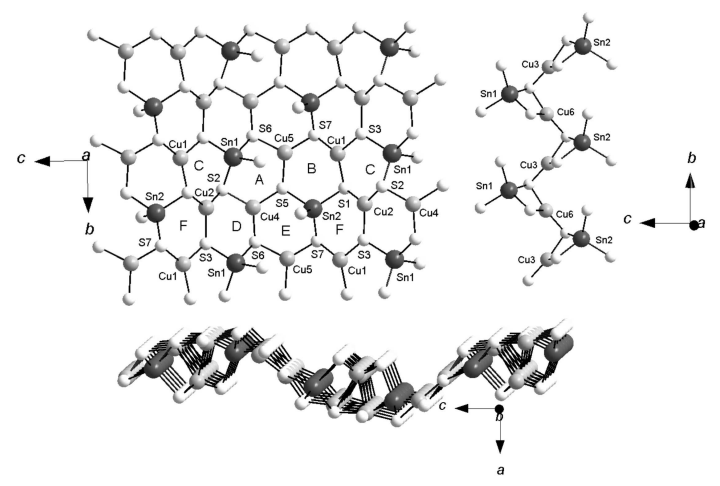

Figure 4: Condensation of the different heterorings in compound 2 forming the anionic layer (top, left). The chain made up by interconnection of $\mathrm{Cu}(3) \mathrm{S}_{3}, \mathrm{Cu}(6) \mathrm{S}_{3}$ and $\mathrm{SnS}_{4}$ tetrahedra (top, right). Bottom: undulated arrangement of a layer (view approximately along the $b$-axis).

Along [001] the sequence of the rings is ...A-B-C-... and ...D-E-F.... $\mathrm{Cu}(3) \mathrm{S}_{3}$ and $\mathrm{Cu}(6) \mathrm{S}_{3}$ units do not participate in these rings and they are joined into chains along [010] by corner-sharing with each other and edge-sharing with the $\mathrm{SnS}_{4}$ tetrahedra (Fig. 4, right). The chains and layers are connected via $\mathrm{S}$ atoms of the $\mathrm{SnS}_{4}$ tetrahedra. This connection scheme leads to the formation of further heterorings like $\mathrm{Cu}(3) \mathrm{Cu}(4) \mathrm{Cu}(5) \mathrm{S}_{3}$ and $\mathrm{Cu}(4) \mathrm{Cu}(6) \mathrm{Sn}(2) \mathrm{S}_{3}$. The 
structural motif of condensed six-membered rings is found in layered thioantimonates like $\left(\mathrm{C}_{4} \mathrm{~N}_{3} \mathrm{H}_{14}\right) \mathrm{Cu}_{3} \mathrm{Sb}_{2} \mathrm{~S}_{5}$ and $\left(\mathrm{C}_{6} \mathrm{~N}_{4} \mathrm{H}_{20}\right)_{0.5} \mathrm{Cu}_{3} \mathrm{Sb}_{2} \mathrm{~S}_{5}{ }^{[49]}$, but was never observed before in thiostannates. The amine molecules are located between the layers with an interlayer distance of about $7.5 \AA$. Short $\mathrm{S} \cdots \mathrm{H}-\mathrm{N}$ separations (S(3)-N(4): 3.162(14) $\AA$ and $\mathrm{S}(3)-\mathrm{N}(2): 3.313(27) \AA)$ indicate weak hydrogen bonding interactions.

\section{In-situ EDXRD investigations}

Solvothermal syntheses often deal with the problem that the products are not phase pure and sometimes even in one reaction mixture thiometalates with different compositions coexist. An example is the synthesis of $\left[\mathrm{Ni}(\text { dien })_{2}\right] \mathrm{Sb}_{4} \mathrm{~S}_{7} \cdot \mathrm{H}_{2} \mathrm{O}$ where the product always contained $\left[\mathrm{Ni}(\mathrm{dien})_{2}\right]_{3}\left(\mathrm{SbS}_{4}\right)_{2}{ }^{[54]}$ as the second phase. In the present case not only two different thiostannates coexist but these two compounds have $\mathrm{Sn}$ in different oxidation states. In the syntheses elemental $\mathrm{Sn}$ and $\mathrm{Cu}$ are applied and obviously complex redox reactions lead to the formation of $\mathrm{Sn}$ (II) and $\mathrm{Sn}(\mathrm{IV})$ in $\mathbf{1}$ and $\mathrm{Sn}(\mathrm{IV})$ in $\mathbf{2}$. A broad variation of the synthesis conditions was performed to increase the yields and to find conditions where only compound $\mathbf{2}$ appears in the final product. But after about 50 syntheses without success the question raised whether the occurrence of the two products is an inherent "problem". Several scenarios can be imagined: (i) both compounds crystallize simultaneously and coexist due to a similar stability; (ii) one of the two compounds is formed first and the second start to grow at later stages of the reaction; for instance, the $\mathrm{Cu}$ containing material (2) appears first and is partially dissolved providing the species for crystallization of $\mathbf{1}$.

The energy range of the spectra was chosen to show at least two reflections of the final products respectively of each compound at the same time. A typical spectrum obtained at the end of a reaction with $\mathrm{Cu}, \mathrm{Sn}, \mathrm{S}$ and DBN shows the $\mathrm{Sn}-\mathrm{K} \alpha$ and $\mathrm{Sn}-\mathrm{K} \beta$ fluorescences as well as the Bragg peaks of the two compounds (Fig. 5).

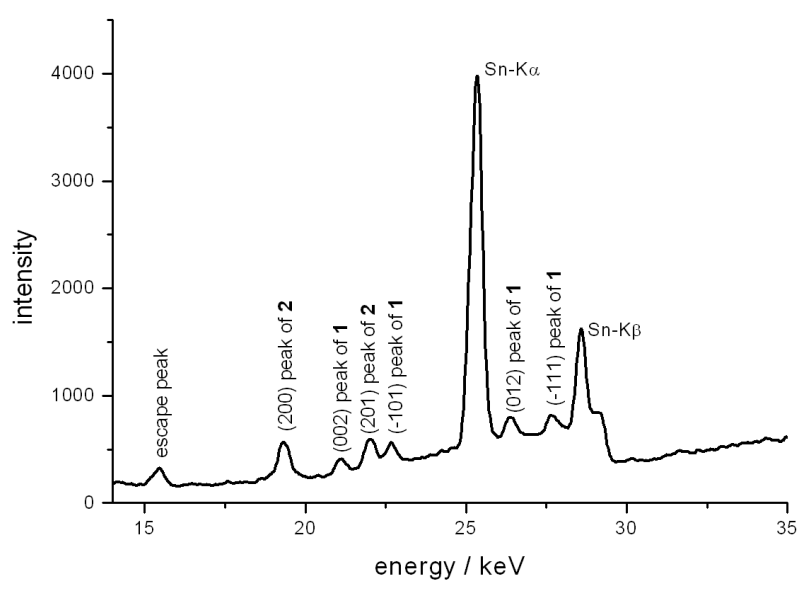

Figure 5: A typical powder pattern recorded at the beamline F3. The Bragg reflections of both compounds and the Sn fluorescences are labelled. The peak at $\sim 15.5 \mathrm{keV}$ is the escape peak of the Ge detector.

The progress of a typical reaction at $160{ }^{\circ} \mathrm{C}$ is shown as timeresolved spectra in Fig. 6 . In the beginning of the reaction only $\mathrm{Sn}$ fluorescences are observable and a crystalline intermediate starts to grow (marked in Fig. 6) after about $8 \mathrm{~min}$. This intermediate survives approximately $60 \mathrm{~min}$ and when this phase has disappeared, the (200) and (201) reflections of 2 become visible after $68 \mathrm{~min}$ and $72 \mathrm{~min}$, respectively. After $110 \mathrm{~min}$ reaction time, the $\mathrm{Cu}$ free compound $\mathbf{1}$ starts to grow with all reflections appearing at the same reaction time.

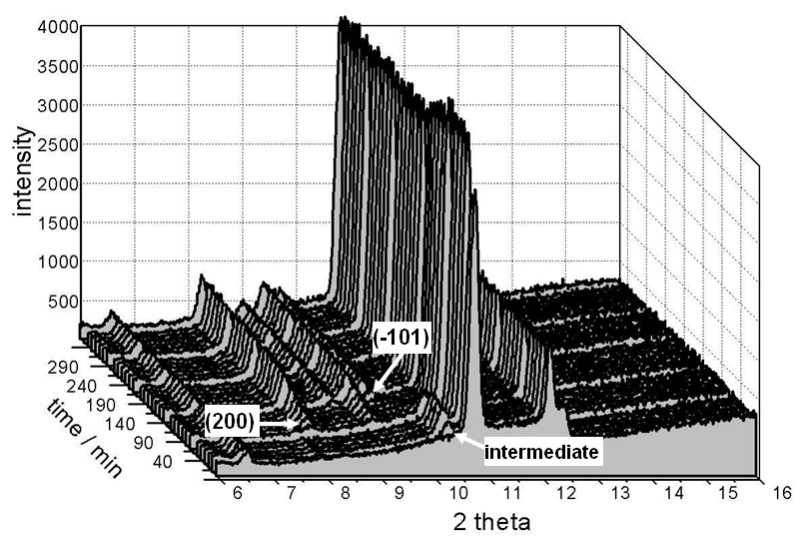

Figure 6: Time resolved powder diffraction patterns of a synthesis at $160{ }^{\circ} \mathrm{C}$. The reflection of the crystalline intermediate, the $(-101)$ of $(\mathrm{DBNH})_{2} \mathrm{Sn}_{3} \mathrm{~S}_{6}$ (1) and the (200) reflection of $(\mathrm{DBNH})_{2} \mathrm{Cu}_{6} \mathrm{Sn}_{2} \mathrm{~S}_{8}$ (2) are marked. The energy is converted to the $2 \theta$ scale applying $\mathrm{Cu}-\mathrm{K} \alpha$ wavelength. The peak at $\sim 6.6^{\circ} 2$ theta is the escape peak of the Ge detector.

First we analyse the crystallisation kinetics of compound 2. The evaluation of the data of $\mathbf{1}$ is difficult due to the relatively low intensity of the reflections and the overlap with reflections of $\mathbf{2}$. In principle a deconvolution of superimposed reflections is possible with the program calf3 (see experimental section) and was also done. But the scattering of the intensity of the two reflections was too large for an unambiguous analysis of the crystallization kinetics. In the literature different models of the crystallization kinetics and the evaluation of appropriate data are well documented. ${ }^{[55-59]}$ In the overwhelming cases kinetics are evaluated on the basis of the Johnson-Mehl-Avrami (JMA) kinetics. Several strict conditions like random nucleation and no hard impingement have to be fulfilled before the JMA kinetics will hold. The JMA kinetics does not take into account that different reactions can occur parallel and/or successive. In addition, it is assumed that the reaction exponent $m$ is temperature and time independent, which is not necessarily the case. Therefore, it is often observed that the experimentally derived reaction exponents differ from the theoretical values.

The kinetic analyses are done by integrating the intensities of the product reflections which are normalized against the intensities of the Sn-K $\alpha$ fluorescence. The experimental data are expressed as the extent of reaction and compared with the theoretical values for solid state kinetics. $\alpha(t)$ is the ratio of the normalized intensity at time $t$ to the intensity at time $t_{\infty}$ and is defined by the following equation:

$$
\alpha(t)=I_{n}(t) / I_{n}\left(t_{\infty}\right) .
$$

Using the Avrami-Eroféev expression the kinetic parameter for the reaction exponent $m$ (Avrami exponent) and the rate constant $k$ can be estimated. The kinetic parameters can also be extracted 
using the Sharp-Hancock plot (SH plot) [56]. The reaction exponent $m$ corresponds to the slope of the curve and the rate constant $k$ is the intercept with the y-axis. If the reaction follows one mechanism over the whole reaction time all experimental data points are on a straight line in a SH plot. Therefore, a change of the mechanism during a reaction can be detected immediately. For the evaluation of the kinetic data the induction time $t_{0}$ was subtracted from the time $t$. The SH plot for the (200) peak of 2 at $160{ }^{\circ} \mathrm{C}$ is shown in Fig. 7.

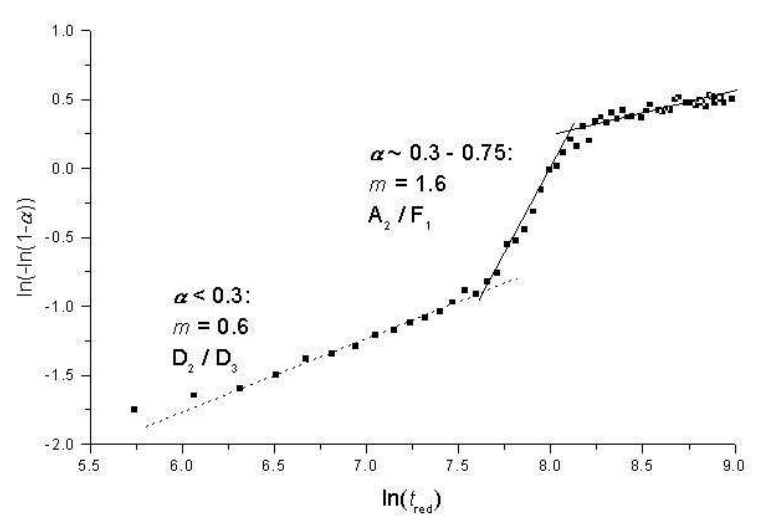

Fig. 7: Sharp-Hancock plot for the reaction at $160^{\circ} \mathrm{C}$ using the (200) reflection of $\mathbf{2}$. The lines are guides for the eyes.

The growth of $\mathbf{2}$ can be roughly divided into three different parts. Up to $\alpha(t) \approx 0.3$, the value for $m$ is about 0.6 which is near models for diffusion control $\mathrm{D}_{2} / \mathrm{D}_{3}$. In the second part $(0.3<\alpha<$ $0.75) \mathrm{m}$ increases to 1.6 indicating a change of mechanism. This value is in between the nucleation Avrami model $\mathrm{A}_{2}$ and a first order reaction $\mathrm{F}_{1}$. For $\alpha>0.75 \mathrm{~m}$ decreases to about 0.4 . In the present case it seems that no simple kinetics dominates the reaction. This is further evidenced by plotting $t / t_{0.5}$ versus $\alpha$ allowing a direct comparison with the established models (Fig. 8).

Analyzing the region between $\alpha(\mathrm{t})=0.1$ and 0.5 (Fig. 8, top) the experimental data points gradually shift from diffusion control to Avrami nucleation models $\mathrm{A}_{2} / \mathrm{A}_{3}$ with increasing reaction time. In Figure 10 the data points between $\alpha(t)=0.4$ and 0.75 suggest that Avrami nucleation models dominate the kinetics. For the later stages of the reaction the data points scatter with a tendency toward a diffusion control. Two different cases can be distinguished for Avrami nucleation: all nuclei form instantaneously (zero order) or nuclei are added during the reaction progress (first order).

The reaction exponent $m$ contains both information and taking into account the two-dimensional nature of the crystals $m \approx 1.6$ implies a two-dimensional growth and instantaneously formation of the nuclei. The deviation of $m$ from the ideal value 2 may be caused by heterogeneous nucleation on the walls of the glass tube. For all temperatures a change of $m$ is observed during the reaction progress with a tendency to later stages of the reaction where the change of $m$ occurs. The reactions performed without $\mathrm{Cu}$ are very fast and all reflections occur simultaneously after short induction times (Fig. 9), and a quantitative evaluation of the reaction kinetics is in this case not possible due to the fast reaction progress.
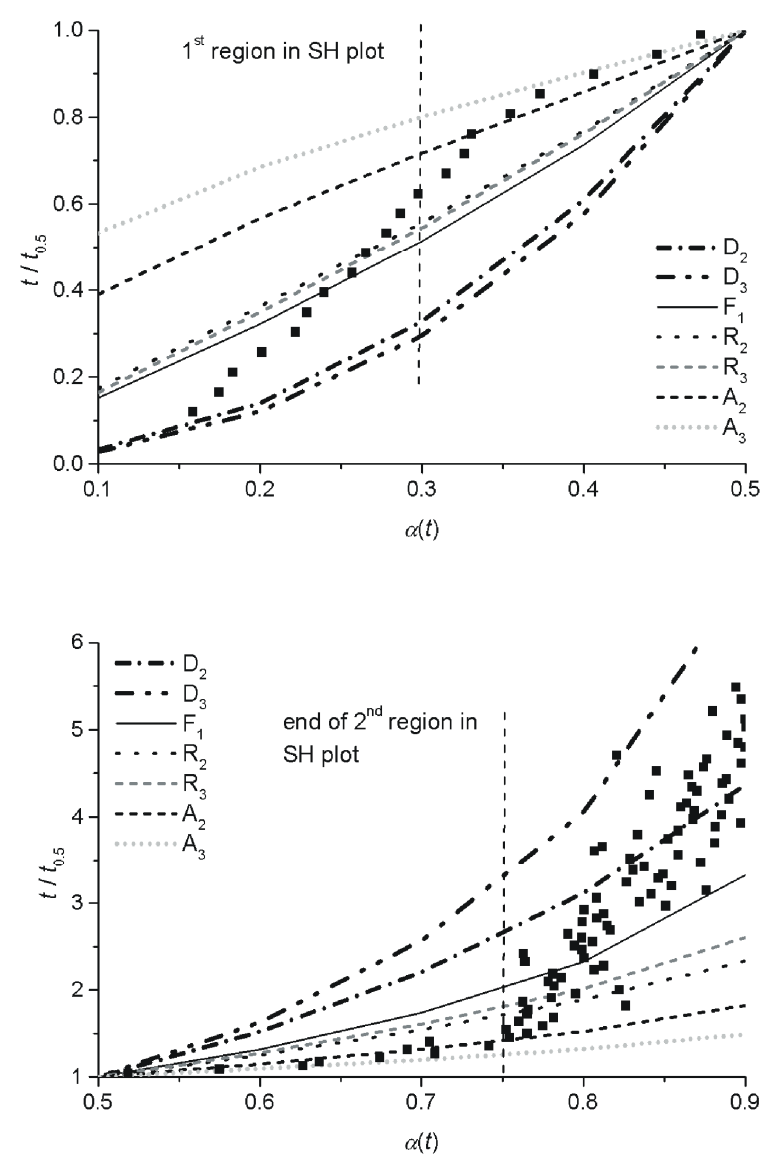

Fig. 8: Comparison of different kinetic models at $160^{\circ} \mathrm{C}$ with the data for the (200) peak.

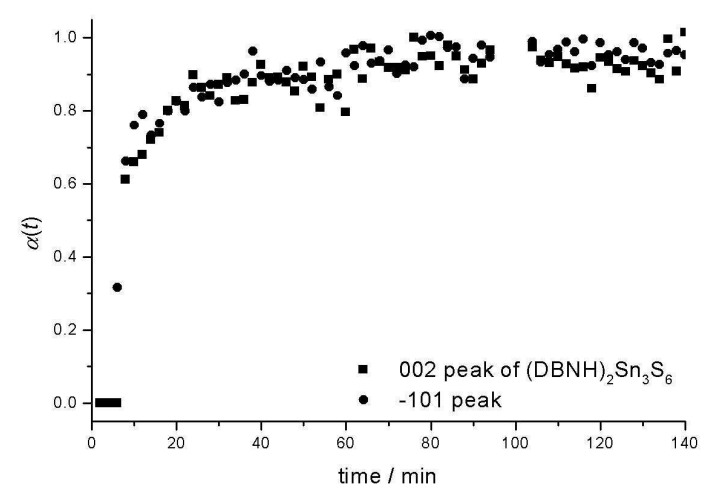

Fig. 9: Extent of reaction for compound 1 at $170{ }^{\circ} \mathrm{C}$ synthesized without $\mathrm{Cu}$ in the reaction mixture.

As mentioned above prior to the formation of $\mathbf{1}$ and $\mathbf{2}$ a crystalline intermediate appears during the syntheses with $\mathrm{Cu}, \mathrm{Sn}$, $\mathrm{S}$ and DBN. In syntheses performed without $\mathrm{Cu}$, no crystalline precursor or intermediate could be observed in the temperature window from 140 to $190{ }^{\circ} \mathrm{C}$. This is a clear indication that the crystalline intermediate species occurs only in the presence of $\mathrm{Cu}$ in the reaction slurry. In addition the presence of $\mathrm{Cu}$ is not required for the crystallization of the mixed-valent compound $\mathbf{1}$, i.e., $\mathrm{Cu}$ is 
not involved in the redox reaction. For the chemical characterization of the crystalline intermediate this phase was isolated by quenching the reaction at different reaction times. For the intermediate quenched after 30, 40, 50 and $60 \mathrm{~min}$ EDX analyses give nearly identical ratios for $\mathrm{Cu}: \mathrm{Sn}: \mathrm{S}$ of about 2:1:6. The CHN content is in agreement with about one DBN molecule assuming $\mathrm{Cu}_{2} \mathrm{SnS}_{6}$ as chemical composition of the inorganic part, i.e., the chemical formula of the intermediate is most likely (DBNH) $\mathrm{Cu}_{2} \mathrm{SnS}_{6}$. Charge neutrality of this compound requires the presence of $\mathrm{S}_{2}{ }^{2-}$ anions assuming $\mathrm{Cu}(\mathrm{I}), \mathrm{Sn}(\mathrm{IV})$ and a double protonated DBN molecule.

More information about the role of the intermediate species for the formation of $\mathbf{1}$ and $\mathbf{2}$ can be extracted by comparing the evolution of the extent of reaction for the intermediate phase and compounds 1 and 2 (Fig. 10). Obviously, compound 2 starts to grow when the intermediate disappeared. The crossing point of $\alpha(t)$ of the intermediate with $\alpha(t)$ of $\mathbf{2}$ is far below about $\alpha=0.2-0.3$, or even at $\alpha=0$. A possible interpretation is that the intermediate is a metastable compound which is destroyed and the more stable compounds start to grow. Furthermore the first reflections of 1 appear when roughly $40 \%$ of compound 2 are formed. At longer reaction times both compounds are in equilibrium supporting the observation of the ex-situ syntheses presented above. Within the experimental accuracy no decrease of the intensity of reflections of $\mathbf{2}$ is observed indicating that $\mathbf{1}$ is not growing at the cost of $\mathbf{2}$. We note that only at $T=160$ and $170{ }^{\circ} \mathrm{C}$ the crystalline intermediate appears. At higher temperatures no reflections of this intermediate were detected and two possibilities can be envisaged as explanation for this observation: the crystalline transient compound is not formed at higher temperatures or the experimental time scale is too slow for the detection of this compound due to a very fast formation and disappearance.

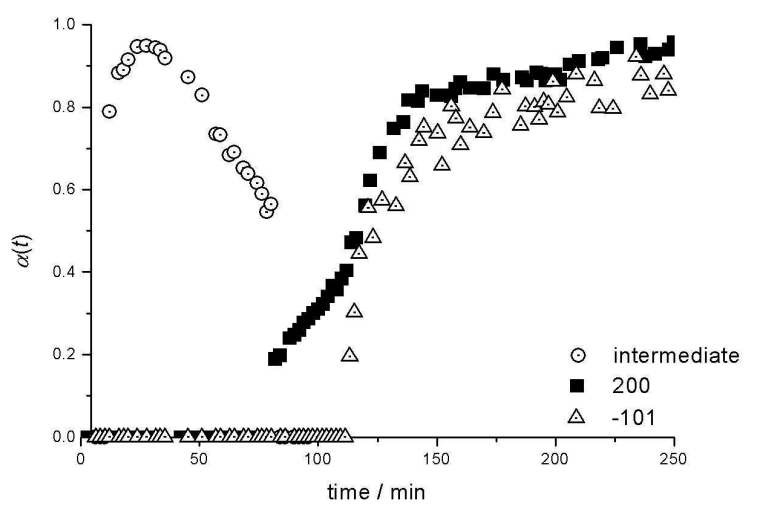

Figure 10: The extent of reaction $\alpha(t)$ for the (200) reflection of $(\mathrm{DBNH})_{2} \mathrm{Cu}_{6} \mathrm{Sn}_{2} \mathrm{~S}_{8}(\mathbf{2})$, the (-101) reflection of $(\mathrm{DBNH})_{2} \mathrm{Sn}_{3} \mathrm{~S}_{6}(\mathbf{1})$ and for the intermediate compound at $160{ }^{\circ} \mathrm{C}$. Note that the scattering of the individual data points is due to the relatively low intensity of the $(-101)$ peak and the reflection of the intermediate.

The temperature dependence of the reactions was investigated between 160 and $190{ }^{\circ} \mathrm{C}$. The time until the first crystallites are observed is the induction time $t_{0}$ which depends on the reaction temperature. Increasing the temperature leads to a significant decrease of $t_{0}$. Typical for solid state kinetics are sigmoidal curves plotting the extent of reaction $\alpha(t)$ versus time. The curves presenting the growth of the (200) reflection of $\mathbf{2}$ at different temperatures are shown in Fig. 11, and the evolution of the crystalline intermediate plotted together with the growth of the (200) reflection of $\mathbf{2}$ and the (-101) reflection of $\mathbf{1}$ at $160{ }^{\circ} \mathrm{C}$ is displayed in Fig. 10.

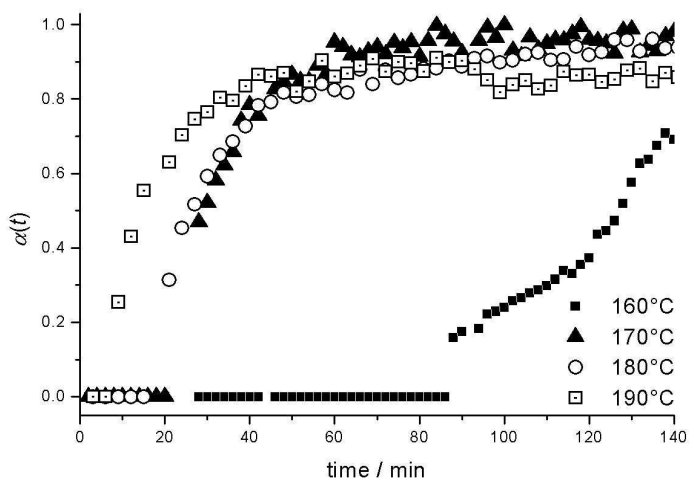

Figure 11: Temperature dependency of the crystallization of $(\mathrm{DBNH})_{2} \mathrm{Cu}_{6} \mathrm{Sn}_{2} \mathrm{~S}_{8}$ (2).

It is interesting to note that $t_{0}$ for the formation of $\mathbf{2}$ is reduced by roughly $60 \mathrm{~min}$ when the temperature is raised from 160 to $170{ }^{\circ} \mathrm{C}$ (Fig. 11). For the reaction temperatures $170-190{ }^{\circ} \mathrm{C}, t_{0}$ is very similar and also the product growth is very fast at these temperatures. In addition, the reactions at higher temperatures are finished after about $100 \mathrm{~min}$.

A qualitative comparison of the reactions applying $\mathrm{Cu}, \mathrm{Sn}, \mathrm{S}$ and DBN with those performed without $\mathrm{Cu}$ clearly demonstrates that the induction time $t_{0}$ is drastically reduced to $20 \mathrm{~min}$ at $160{ }^{\circ} \mathrm{C}$ (110 min with $\mathrm{Cu}$ ) and to $4 \mathrm{~min}$ at $190{ }^{\circ} \mathrm{C}$ (42 min with $\mathrm{Cu}$ ). In the competitive crystallization it seems that the formation of $\mathbf{2}$ is preferred and the growth of $\mathbf{1}$ is inhibited.

The sizes of the coherent scattering particles of both compounds can be estimated applying the Scherrer equation:

$$
D_{k}=\frac{K \cdot \lambda \cdot 180 / \pi}{d_{F W H M} \cdot \cos \theta}
$$

with $D_{\mathrm{k}}$ average crystallite size, $d_{\mathrm{FWHM}}$ full width half maximum, $\theta$ Bragg angle, $\lambda$ wavelength and $K$ the Scherrer constant ( 0.89 was used). The value for $d_{\text {FWHM }}$ of the (200) peak of $2\left(\theta=4.14^{\circ}\right)$ decreases from 0.22 to $0.16^{\circ}$ during the reaction $(t=$ $240 \mathrm{~min}$ ) leading to an increase of the coherent scattering domains from 36 to $49 \mathrm{~nm}$. The $d_{\mathrm{FWHM}}$ for the (002) reflection of $\mathbf{1}$ ( $\theta=$ $4.72^{\circ}$ ) is reduced from 0.2 to $0.17^{\circ}$ yielding sizes of 39 and $46 \mathrm{~nm}$, respectively.

Ex-situ experiments were performed for further exploration of the role of the intermediate for the formation of $\mathbf{1}$ and $\mathbf{2}$. Treating the intermediate with DBN at $160{ }^{\circ} \mathrm{C}$ for $5 \mathrm{~h}$, elemental crystalline $\mathrm{Sn}$ and an amorphous phase containing $\mathrm{Cu}$, Sn and $\mathrm{S}$ are formed. The reaction under similar conditions adding also $\mathrm{S}$ produces $\mathrm{Sn}$ 
and $\mathrm{Cu}$ sulfides. But in the XRD a peak at $7.7^{\circ} 2 \theta$ is observed which cannot be explained with known $\mathrm{Sn} / \mathrm{Cu}$ sulfides or the title compounds. Several experiments were conducted with the intermediate applying different reaction conditions. But in all cases the title compounds were not formed. Two important conclusions can be drawn from this observation: (i) in accordance with the results of the in-situ EDXRD investigations the transient crystalline compound can be regarded as a new material which is not necessary for the formation of $\mathbf{1}$ and $\mathbf{2}$. (ii) Under the real solvothermal conditions soluble species are present which are important for the formation of $\mathbf{1}$ and $\mathbf{2}$.

Further experiments were done to explore whether $\mathbf{1}$ can be transformed to 2 . $\mathrm{Cu}, \mathrm{S}$ and DBN were added to a small amount of 1 and heated at $170{ }^{\circ} \mathrm{C}$ for $5 \mathrm{~h}$. The EDX analysis yields a $\mathrm{Cu} / \mathrm{Sn} / \mathrm{S}$ ratio of $3 / 1 / 4$, but the powder diffraction pattern confirms the presence of $\mathbf{1}$ and $\mathbf{2}$.

\section{Spectroscopy}

Raman spectroscopy: In the Raman spectra the resonances of compound $\mathbf{1}$ at $367,336,313$ and $258 \mathrm{~cm}^{-1}$ are in the typical region for $\mathrm{Sn}-\mathrm{S}$ resonances. ${ }^{[60,61]}$ The symmetric $\mathrm{Sn}-\mathrm{S}$ stretch vibration is located at $367 \mathrm{~cm}^{-1}$ and symmetric Sn-S $S_{\text {bridging }}$ modes appear at 336 and $313 \mathrm{~cm}^{-1}$. The resonance at $258 \mathrm{~cm}^{-1}$ is caused by a $\mathrm{Sn}_{2} \mathrm{~S}_{2}$ ring vibration. For compound $\mathbf{2}$ only two modes are observed. The band at $362 \mathrm{~cm}^{-1}$ is the symmetric Sn-S stretching and that at $332 \mathrm{~cm}^{-1}$ the symmetric $\mathrm{Sn}-\mathrm{S}_{\text {bridging }}$ vibration. Surprisingly, no resonances or modes caused by $\mathrm{Cu}-\mathrm{S}$ vibrations are observed.

UV/Vis spectroscopy: The optical band gap was determined from transformed UV/Vis diffuse reflectance spectra with the Kubelka-Munk-method. For $1 \mathrm{E}_{\mathrm{g}}$ amounts to $2.6 \mathrm{eV}(477 \mathrm{~nm})$ in agreement with the yellow color. The value for 2 of $1.84 \mathrm{eV}$ (674 $\mathrm{nm})$ is in accordance with the red color of the plates.

\section{Thermal Stability}

Compound 1 decomposes in two steps. The first thermal reaction starts at $T_{\text {onset }}=229{ }^{\circ} \mathrm{C}\left(T_{\text {peak }}=234{ }^{\circ} \mathrm{C}\right)$ and is associated with a mass loss of $11.2 \%$. The next step occurs at $T_{\text {onset }}=288^{\circ} \mathrm{C}$ $\left(T_{\text {peak }}=310^{\circ} \mathrm{C}\right)$ with a weight change of $21.5 \%$. The difference between observed and calculated weight loss $\left(-\Delta m_{\text {theo }}(2 \mathrm{DBN}+1\right.$ $\left.\mathrm{H}_{2} \mathrm{~S}\right)=35.3 \%$ ) can be explained with a contamination (CHN) of the residue. The decomposition product is black and $\mathrm{SnS}$ was identified in the powder pattern.

The thermal decomposition of compound 2 starts at $T_{\text {onset }}=$ $218{ }^{\circ} \mathrm{C}\left(T_{\text {peak }}=281^{\circ} \mathrm{C}\right)$ with a related weight loss of $28.9 \%$ which is slightly higher than the calculated value $\left(-\Delta m_{\text {theo }}\left(\mathrm{DBN}+\mathrm{H}_{2} \mathrm{~S}\right)=\right.$ $28.3 \%)$. The obtained powder is black and contains a few percent of CHN. The compounds $\mathrm{SnS}$ and $\mathrm{CuS}$ were identified in the powder pattern.

\section{Conclusions}

Under solvothermal conditions the new thiostannates $(\mathrm{DBNH})_{2} \mathrm{Sn}_{3} \mathrm{~S}_{6}$ (1) and $(\mathrm{DBNH})_{2} \mathrm{Cu}_{6} \mathrm{Sn}_{2} \mathrm{~S}_{8}$ (2) were obtained simultaneously as yellow needles and red plates respectively. The quality of the crystals could be increased applying longer reaction times. The simultaneous occurrence of the mixed-valent thiostannate $\mathbf{1}$ and a $\mathrm{Sn}(\mathrm{IV})$ containing $\mathrm{Cu}$ thiostannate $\mathbf{2}$ is of special interest. Obviously, a complex redox reaction occurs during synthesis progress.

The $\mathrm{Sn}(\mathrm{II})$ atom in $\mathbf{1}$ is in a trigonal pyramidal coordination which is quite rare. The layered structure of $\mathbf{2}$ may be viewed as an inorganic $6^{3}$ graphene layer constructed by condensation of $\mathrm{CuS}_{3}$ triangles and $\mathrm{SnS}_{4}$ tetrahedra. Such a structural motif was never observed before in the structures of thiostannates.

Despite a large variation of several synthesis parameters, compound 2 could not be obtained as phase pure product. In-situ EDXRD experiments not only reveal that $\mathbf{1}$ and $\mathbf{2}$ start to crystallize within a narrow time window but also highlights the occurrence of a crystalline intermediate prior to formation of $\mathbf{1}$ and 2. This intermediate is a new metastable compound which is not simply transformed into the final products. The quenched metastable compound could not be transformed into one of the two stable compounds. The successful preparation of the $\mathrm{Sn}(\mathrm{II}) / \mathrm{Sn}$ (IV) compound demonstrates that neither the intermediate nor $\mathrm{Cu}$ is directly involved in the complex redox reaction. The in-situ experiments also show that crystallization of $\mathbf{1}$ is retarded in the presence of $\mathrm{Cu}$ species in the solution. The results of in-situ experiments of reactions with only Sn, S, and DBN demonstrate that $\mathbf{2}$ is formed within a couple of minutes. Such information cannot be acquired using only ex-situ syntheses.

Despite the large amount of information acquired during the studies several synthetic challenges are left open. For instance, it would be of great interest to synthesize the metastable intermediate for structural characterization. The challenge is finding synthesis conditions where only this metastable compound is formed, or at least crystals of appropriate quality are present. It is also necessary synthesizing phase pure material of $\mathbf{2}$, and further explorative syntheses with different $\mathrm{Cu}$ and $\mathrm{Sn}$ compounds are under way. But changing the starting material requires a large number of experiments until the reaction conditions for the formation of a desired compound are established.

\section{Experimental Section}

\section{Syntheses:}

General: All chemicals were purchased (see below for purity and company) and used without further purifications. Both compounds were prepared under solvothermal conditions in teflon-lined steel autoclaves (inner volume: $30 \mathrm{~mL}$ ). The crystalline reaction products were filtered off, washed with water and ethanol and dried in vacuum.

Synthesis of $(\mathrm{DBNH})_{2} \mathrm{Sn}_{3} \mathrm{~S}_{6}(\mathbf{1})$ and $(\mathrm{DBNH})_{2} \mathrm{Cu}_{6} \mathrm{Sn}_{2} \mathrm{~S}_{8}(2): 118.7 \mathrm{mg}(1 \mathrm{mmol}) \mathrm{Sn}$ (99.5\%, Aldrich), $63.5 \mathrm{mg}$ (1 mmol) Cu (99.5\%, Alfa Aesar), $105.8 \mathrm{mg}(3.3 \mathrm{mmol}) \mathrm{S}$ in $3 \mathrm{~mL}$ of 1,5-diazabicyclo[4.3.0]non-5-ene (DBN) ( $\geq 98.0 \%$, Fluka) were reacted for $27 \mathrm{~d}$ at $140{ }^{\circ} \mathrm{C}$, followed by cooling to $25^{\circ} \mathrm{C}$ in $30 \mathrm{~h}$. In the reaction products yellow needles of $\mathbf{1}$ and red plates of $\mathbf{2}$ were found in a total yield of $30 \mathrm{mg}(10.4 \%)$. 
The compounds can also be obtained applying a reaction time of $5 \mathrm{~d}$, but the quality of the crystals especially for $\mathbf{2}$ was not good enough for single crystal structure determination. During the optimization of the reaction conditions, the duration was elongated from $5 \mathrm{~d}$ over 10 and $15 \mathrm{~d}$ up to $27 \mathrm{~d}$. In all syntheses $\mathrm{Cu}$ and $\mathrm{Sn}$ sulfides are the main products. A large number of syntheses was performed to increase the yield and also the homogeneity.

1 can also be synthesized reacting $1 \mathrm{mmol} \mathrm{Sn}$ and $3 \mathrm{mmol} \mathrm{S}$ in $3 \mathrm{~mL} \mathrm{DBN}$ for $20 \mathrm{~d}$ at $170{ }^{\circ} \mathrm{C}$ in a yield of $25 \mathrm{mg}(11.1 \%)$. The different reaction products were manually separated and the homogeneity of both compounds was confirmed by X-ray powder diffraction. Elemental analyses (results in \%): 1: $\mathrm{C}_{14} \mathrm{H}_{26} \mathrm{~N}_{4} \mathrm{Sn}_{3} \mathrm{~S}_{6}$ (798.82): calcd. C 21.10, H 3.04, N 7.03; found: C 21.05, H 3.21, N 7.11; 2: $\mathrm{C}_{14} \mathrm{H}_{26} \mathrm{~N}_{4} \mathrm{Cu}_{6} \mathrm{Sn}_{2} \mathrm{~S}_{8}$ (1125.49): calcd. C 14.94, H 2.33, N 4.98; found: C 14.82, H 2.46, N 4.81

\section{Structure determination:}

Intensity data were collected on a STOE IPDS-1 (Imaging Plate Diffraction System) with Mo-K $\alpha$ radiation at room temperature. The structures were solved with direct methods using the program SHELXS-97 [62] and the refinements were done against $\mathrm{F}^{2}$ with SHELXL-97 [63]. Anisotropic displacement parameters were used for all nonhydrogen atoms. The $\mathrm{H}$ atoms of the amines were positioned with idealized geometry and refined using a riding model and a fixed isotropic displacement parameter. In 2 some disorder of the DBN is present and the structure refinement was performed using a split model. Some selected refinement results are summarized in Table 3 .

Table 3: Selected technical details of data collection and results of the structure refinement of the title compounds.

\begin{tabular}{|l|l|l|}
\hline & $(\mathrm{DBNH})_{2} \mathrm{Sn}_{3} \mathrm{~S}_{6}$ & $(\mathrm{DBNH})_{2} \mathrm{Cu}_{6} \mathrm{Sn}_{2} \mathrm{~S}_{8}$ \\
\hline Crystal system & Monoclinic & Orthorhombic \\
\hline Space group & $P 2_{1} / n$ & $P c a 2_{1}$ \\
\hline$a / \AA$ & $9.5822(8)$ & $21.3017(10)$ \\
\hline$b / \AA$ & $13.1199(7)$ & $6.6837(3)$ \\
\hline$c / \AA$ & $19.9506(16)$ & $19.9480(13)$ \\
\hline$\alpha$ & 90 & 90 \\
\hline$\beta$ & $97.192(10)$ & 90 \\
\hline$\gamma$ & 90 & 90 \\
\hline$V / \AA^{3}$ & $2488.4(3)$ & $2840.1(3)$ \\
\hline$Z$ & 4 & 4 \\
\hline$\rho_{\text {calc }} / \mathrm{g} \cdot \mathrm{cm}^{-3}$ & 2.132 & 2.632 \\
\hline$\mu / \mathrm{mm}^{-1}$ & 3.501 & 6.734 \\
\hline Scan Range & $2.65 \leq \Theta \leq 28.02^{\circ}$ & $2.80 \leq \Theta \leq 28.02^{\circ}$ \\
\hline Reflections collected & 21603 & 16982 \\
\hline Refl. with $F_{o}>4 \sigma\left(F_{o}\right)$ & 1536 & 2160 \\
\hline Independent reflections & $5831\left[\mathrm{R}_{\text {int }}=0.0589\right]$ & $6810\left[\mathrm{R}_{\text {int }}=0.0636\right]$ \\
\hline Goodness-of-fit on $\mathrm{F}^{2}$ & 1.006 & 0.985 \\
\hline Final $R$ & $R I=0.0387$, & $R I=0.0441$, \\
{$[I>2 \sigma(I)]$} & $w R 2=0.0874$ & $w R 2=0.1031$ \\
\hline$R$ indices (all data) & $R I=0.0626$, & $R I=0.0597$, \\
\hline Res. Elec. Dens. / e. $\AA^{-3}$ & $w R 2=0.0958$ & $w R 2=0.1108$ \\
\hline Flack $x$ parameter & $0.928 /-0.971$ & $1.667 /-1.634$ \\
\hline \multicolumn{2}{|c|}{} & $-0.02(2)$ \\
\hline
\end{tabular}

Further crystallographic details have been deposited with the Cambridge Crystallographic Data Centre as publication no. CCDC 709992 (1) and CCDC 709993 (2). Copies of the data can be obtained, free of charge, on application to CCDC, 12 Union Road, Cambridge CB2 1 EZ, UK (mail: deposit@ccdc.ca.ac.uk).

Energy Dispersive X-Ray Diffraction (EDXRD):

All EDXRD experiments were carried out at the HASYLAB beamline F3 at DESY, Hamburg, Germany. The beamline station receives white synchrotron radiation from a bending magnet with $E_{\mathrm{c}}=16.6 \mathrm{keV}$ and gives a positron beam energy of $4.5 \mathrm{GeV}$. The energy range from 6 to $60 \mathrm{keV}$ exhibits a maximum at about $20 \mathrm{keV}$. A liquid nitrogen cooled solid-state germanium detector with a resolution of about $1 \%$ was used. The angle of the detector was fixed at approximately $1.8^{\circ}$ which allowed the detection of the Bragg reflections and the observable $d$-spacing range was 3.1 to $32.3 \AA$ given by $E$ $=6.199 /(d \cdot \sin \theta)$. The beam was collimated to $200 \times 200 \mathrm{~mm}$ giving the best results. More experimental details can be found in $[30,31]$. The in-situ investigations were conducted in glass tubes in special autoclaves with an internal diameter of $10 \mathrm{~mm}$ and a volume of $7 \mathrm{~mL}$. The delay time between filling the mixture of the starting materials in the autoclave and starting the reaction was about $2 \mathrm{~min}$ and the reaction temperature was reached within $1 \mathrm{~min}$. Time-resolved X-ray powder patterns with acceptable counting statistics could be recorded with acquisition times between 120 and $180 \mathrm{sec}$. Under stirring conditions the compounds were synthesized using $30 \mathrm{mg}(0.47 \mathrm{mmol})$ $\mathrm{Cu}, 60 \mathrm{mg}(0.5 \mathrm{mmol}) \mathrm{Sn}$ and $50 \mathrm{mg}(1.55 \mathrm{mmol}) \mathrm{S}$ in $1 \mathrm{~mL}$ DBN at temperatures ranging from 140 to $200{ }^{\circ} \mathrm{C}$. Compound 1 was prepared applying $60 \mathrm{mg} \mathrm{Sn}(0.5$ $\mathrm{mmol})$ and $50 \mathrm{mg} \mathrm{S}(1.55 \mathrm{mmol})$ in $1 \mathrm{~mL} \mathrm{DBN}$ at temperatures between 140 and $190{ }^{\circ} \mathrm{C}$. The resulting spectra were evaluated with EDXPowd [64] and the Origin6.0 program package. Due to some problems in integrating triple peaks of spectra series, we used the program "calf3" which was developed in close cooperation with A. Rothkirch (Hasylab, DESY). It was written to support the energy calibration of beamline F3 and to evaluate spectra time series of in-situ EDXRD measurements. The routine is written in Interactive Data Language (IDL), ITT Visual Information Solutions, Boulder, CO, USA and runs also with IDL virtual machine. For the data evaluation of time series, an input file must be supplied which provides regions of interest for possible peak positions and (optional) regions for background. The data are background corrected by a polynomial assumption and regions of interest are scanned for diffraction/fluorescence peaks. The peaks are fitted to Gaussians (possible for single or even superimposed triple peaks) and separately integrated for every single spectrum. In addition, a normalization of the integrals to a reference can be applied (e.g. integral of fluorescence peak within a single spectrum). The derived coefficients and integrals are written to an output file as well as an illustration for first visual analysis. The integrals of the product reflections were normalized with the integrals of the intensity of the $\mathrm{Sn}-\mathrm{K} \alpha$ fluorescence.

\section{X-Ray Powder Diffraction}

$\mathrm{X}$-ray powder diffraction patterns were recorded in transmission mode with a STOE Stadi-P diffractometer equipped with an imaging plate position sensitive detector (IP$\mathrm{PSD})$ and $\mathrm{Ge}$ monochromator using $\mathrm{Cu}-\mathrm{K} \alpha 1(\lambda=1.54056 \AA)$ radiation.

\section{Thermal investigations:}

DTA-TG experiments were carried out using a Netzsch STA 429 DTA-TG device. The samples were heated up to $500{ }^{\circ} \mathrm{C}$ with $4 \mathrm{~K} \cdot \mathrm{min}^{-1}$ under a flow of argon $(75$ $\left.\mathrm{mL} \cdot \mathrm{min}^{-1}\right)$ in $\mathrm{Al}_{2} \mathrm{O}_{3}$ crucibles. The TG data were corrected for buoyancy and current effects.

Scanning electron microscopy (SEM)/ energy dispersive X-ray fluorescence (EDX): A Philips ESEM XL30 equipped with an EDAX EDX system was used to determine the compositions.

Spectroscopic experiments:

Infrared spectroscopy: In the IR spectra the absorptions located at $3277(\mathrm{~m},-\mathrm{NH}$ stretch), 3104 (m, -NH stretch), 2922 (s, - $\mathrm{CH}_{2}$; m-s, -NH stretch), 1670 (m, -CC), 1567 $(\mathrm{m}-\mathrm{s},-\mathrm{NH}), 1417,1298,1201(\mathrm{~m},-\mathrm{CN})$ and $1064(\mathrm{~m},-\mathrm{CN}) \mathrm{cm}^{-1}(\mathbf{1})$ respectively at 2920 (s, - $\mathrm{CH}_{2}$; m-s, -NH stretch), 1670 (m, -CC), 1371, 1292, 1124 (m, -CN) and 1064 $(\mathrm{m},-\mathrm{CN}) \mathrm{cm}^{-1}(\mathbf{2})$ are detected of the DBN molecules.

Raman: The data for the Raman spectra were collected in the region from 100 to 500 $\mathrm{cm}^{-1}$ with a Bruker IFS 66 Fourier Transform Raman spectrometer (wavelength: 541.5 $\mathrm{nm})$.

UV/Vis: Investigations were done at room temperature using a UV-VIS-NIR twochannel spectrometer Cary 5 from Varian Techtron Pty., Darmstadt. The absorption data were calculated with the Kubelka-Munk approach for diffuse reflectance data. $\mathrm{BaSO}_{4}$ powder was used as reference material.

Elemental analysis:

CHNS analyses were done using a EURO EA Elemental Analyzer, fabricated by EURO VECTOR Instruments and Software. 
Supporting Information (see footnote on the first page of this article):

\section{Acknowledgments}

We thank the Hasylab, DESY, Hamburg, Germany, for the measurement times at the beamline F3. Thanks to Beatrix Seidlhofer and Elena Antonova (University of Kiel) for joining our measurements and thanks to André Rothkirch (Hasylab, DESY, Hamburg) for his help.

[1] M. Behrens, C. Näther, W. Bensch, Z. Anorg. Allg. Chem. 2002, 628 2160 .

[2] C. Näther, S. Scherb, W. Bensch, Acta Cryst. 2003, E59, m280$\mathrm{m} 282$.

[3] A. Puls, C. Näther, W. Bensch, Acta Cryst. 2005, E61, m868-m870.

[4] J.B. Parise, Y. Ko, J. Rijssenbeek, D.M. Nellis, K. Tan, S. Koch, J. Chem. Soc., Chem. Commun. 1994, 527.

[5] T. Jiang, A. Lough, G.A. Ozin, Adv. Mater. 1998, 10, 42-46.

[6] T. Jiang, A. Lough, G.A. Ozin, R.L. Bedard, R. Broach, J. Mater. Chem. 1998, 8, 721-732.

[7] S. Dehnen, C. Zimmermann, Z. Anorg. Allg. Chem. 2002, 628, 24362439 .

[8] R.W.J. Scott, M.J. MacLachlan, G.A. Ozin, Current Opinions in Solid State and Materials Science 1999, 4, 113-121.

[9] T. Jiang, G.A Ozin, J. Mater. Chem. 1997, 7, 2213-2222.

[10] R.J. Francis, S.J. Price, J.S.O. Evans, S. O'Brien, D. O'Hare, S.M. Clark, Chem. Mater. 1996, 8, 2102-2108.

[11] Y. An, M. Ji, M. Baiyin, X. Liu, C. Jia, D. Wang, Inorg. Chem. 2003, $14,4248-4249$.

[12] M. Behrens, S. Scherb, C. Näther, W. Bensch, Z. Anorg. Allg. Chem. 2003, 629, 1367-1373.

[13] N. Pienack, W. Bensch, Z. Anorg. Allg. Chem. 2006, 632, 1733-1736.

[14] N. Pienack, C. Näther, W. Bensch, Solid State Sci. 2007, 9, 100-107.

[15] D.X. Jia, J. Dai, Q.Y. Zhu, Y. Zhang, X.M. Gu, Polyhedron 2004, 23, 937-942.

[16] M. Antonietti, G.A. Ozin, Chem. Eur. J. 2004, 10, 28-41.

[17] M. Cruz, J. Morales, J.P. Espinos, J. Sanz, J. Solid State Chem. 2003, $175,359-365$.

[18] K.O. Klepp, F. Fabian, Z Naturforsch B 1992, 47, 406-410.

[19] K.O. Klepp, F. Fabian, European Crystallographic Meeting 1994, 15, 626-626.

[20] S. Chitsaz, B. Neumüller, K. Dehnicke, Z. Anorg. Allg. Chem. 2000, $626,318-815$.

[21] J.F. Eichler, O. Just, W.S. Rees, Inorg. Chem. 2006, 45, 6706-6712.

[22] C. Adenis, J. Olivier-Fourcade, J.C. Jumas, E. Philippot, Rev. Chim. Min. 1986, 23, 735-745.

[23] C. Adenia, J. Olivier-Fourcade, J.C. Jumas, E. Philippot, Eur. J. Solid State Inorg. Chem. 1988, 25, 413-423.

[24] J.C. Jumas, J. Olivier-Fourcade, E. Philippot, M. Maurin, Rev. Chim. Min. 1979, 16, 48-59.

[25] S. Jobic, P. le Boterf, R. Brec, G. Ouvrard, J. Alloys Compd. 1994, 205, 139-145.

[26] R. Francis, D. O'Hare, J. Chem. Soc., Dalton Trans. 1998, 3133.

[27] W. Bensch, C. Näther, R. Stähler, Chem. Commun. 2001, 477-478.

[28] R. Stähler, B.D. Mosel, H. Eckert, W. Bensch, Angew. Chem. Int Ed., 2002, 41, 4487-4489.
[29] R. Kiebach, F. Studt, C. Näther, W. Bensch, Eur. J. Inorg. Chem. 2004, 2553-2556.

[30] L. Engelke, M. Schaefer, M. Schur, W. Bensch, Chem. Mater. 2001, 13, 1383-1390.

[31] L. Engelke, M. Schaefer, F. Porsch, W. Bensch, Eur. J. Inorg. Chem. 2003, 506-513.

[32] R. Kiebach, M. Schaefer, F. Porsch, W. Bensch, Z. Anorg. Allg. Chem. 2004, 631, 369-374.

[33] R. Kiebach, N. Pienack, M.E. Ordolff, F. Studt, W. Bensch, Chem. Mater. 2006, 18, 1196-1205.

[34] A. Michailovski, J.-D. Grunwaldt, A. Baiker, R. Kiebach, W. Bensch, G.R. Patzke, Angew. Chem. 2005, 117, 5787-5792; Angew. Chem. Int. Ed. 2005, 44, 5643-5647.

[35] A. Michailovski, R. Kiebach, W. Bensch, J.-D. Grunwaldt, A. Baiker, S. Komarneni, G.R. Patzke, Chem. Mater. 2007, 19, 185-197.

[36] R. Kiebach, N. Pienack, W. Bensch, J.-D. Grunwaldt, A. Michailovski, A. Baiker, T. Fox, Y. Zhou, G.R. Patzke, Chem. Mater. 2008, 20, 3022-3033.

[37] R.I. Walton, T. Loiseau, D. O’Hare, G. Férey, Chem. Mater. 1999, 11, 3201-3209.

[38] K. Tan, Y. Ko, J.B. Parise, Acta Cryst. 1995, C51, 398.

[39] T. Jiang, A.J. Lough, G.A. Ozin, D. Young, R.L. Bedard, Chem. Mater. 1995, 7, 245-248.

[40] O. Slupecki, I.D. Brown, Acta Cryst. 1982, B38, 1078-1079.

[41] R. Kniep, D. Mootz, U. Severin, H. Wunderlich, Acta Cryst. 1982, B $38,2022$.

[42] J.J. Vittal, P.A.W. Dean, Acta Crystallogr. Sect.C: Cryst. Struct. Commun. 1996, 52, 1180

[43] P.A.W. Dean, J.J. Vittal, N.C. Payne, Can. J. Chem. 1985, 63, 394.

[44] G. Barone, T.G. Hibbert, M.F. Mahon, K.C. Molloy, I.P. Parkin, L.S. Price, I. Silaghi-Dumitrescu, J. Chem. Soc., Dalton Trans. 2001, 3435 .

[45] T. Jiang, A. Lough, G.A. Ozin, R.L. Bedard, J. Mater. Chem. 1998, 8, 733-741.

[46] W.S. Sheldrick, B. Schaaf, Z. Anorg. Allg. Chem. 1994, 620, 10411045.

[47] T. Jiang, G.A. Ozin, J. Mater. Chem. 1998, 8, 1099-1108.

[48] T. Jiang, G.A. Ozin, R.L. Bedard, J. Mater. Chem. 1998, 8, 16411648.

[49] X. Chen, H. Wada, A. Sato, M. Mieno, J. Solid State Chem. 1998, $139,144-151$

[50] X. Chen, H. Wada, A. Sato, Mater. Res. Bull. 1999, 34, 239.

[51] V. Spetzler, H. Rijnberk, C. Näther, W. Bensch, Z. Anorg. Allg. Chem. 2004, 630, 142-148.

[52] V. Spetzler, C. Näther, W. Bensch, Inorg. Chem. 2005, 44, 58055812.

[53] M. Jansen, Angew. Chem. 1987, 99, 1136-49; Angew. Chem. Int. Ed. Engl. 1987, 26, 1098-1110.

[54] R. Stähler, C. Näther, W. Bensch, J. Solid State Chem. 2003, 174, 264-275.

[55] M.J. Avrami, Chem. Phys. 1939, 7, 1103-1112.

[56] M.J. Avrami, Chem. Phys. 1940, 8, 212-224.

[57] M.J. Avrami, Chem. Phys. 1941, 9, 177-184.

[58] J.H. Sharp, G.W. Brindley, B.N. Narahari Achar, J. Am. Cer. Soc. 1966, 47, 379-382.

[59] J.D. Hancock, J.H. Sharp, J. Am. Cer. Soc. 1972, 55, 74-76.

[60] B. Krebs, W. Schiwy, Z. Anorg. Allg. Chem. 1973, 398, 63-71.

[61] B. Krebs, S. Pohl, W. Schiwy, Angew. Chem. 1970, 82, 884-885; Angew. Chem. Int. Ed. Engl. 1970, 9, 897-898. 
[62] G.M. Sheldrick, SHELXS 97, Program for the Solution of Crystal Structures, University of Göttingen, Germany, 1997.

[63] G.M. Sheldrick, G.M., SHELXL 97, Program for the Refinement of Crystal Structures, University of Göttingen, Germany, 1997.

[64] F. Porsch, EDXPowd Version 3.155, RTI GmbH, Paderborn, Germany, 2004.
Received: ((will be filled in by the editorial staff)) Published online: ((will be filled in by the editorial staff)) 
Coexistence of a $\mathrm{Sn}(\mathrm{II}) / \mathrm{Sn}(\mathrm{IV})$ and a $\mathrm{Cu}$ containing Sn(IV) thiostannate under solvothermal conditions.

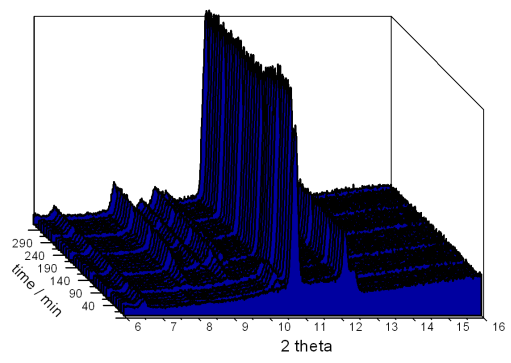

N. Pienack, C. Näther, W. Bensch*

Solvothermal Syntheses of Two New Thiostannates and an In-situ

Energy Dispersive X-Ray

Scattering Study of their

Formation

Keywords: Solvothermal Synthesis / Crystal Structure / In-situ EDXRD /

Thiostannates 